\title{
INSERÇ̃̃O DO ENFERMEIRO NA PROFISSÃO: UMA ABORDAGEM RELACIONAL DE SUA FORMAC̣ÃO COM A VIVÊNCIA PROFISSIONAL
}

\author{
Sônia Maria Vilella Bueno* \\ Edna Paciência Vietta* \\ Dulce M. Vendrusculo de Freitas**
}

\begin{abstract}
RESUMO - Preocupados com o momento atual de mudanças na prática e no ensino de enfermagem, tendo em vista as várias contribuições propostas para os currículos de graduação de enfermagem e a necessidade de um maior engajamento de todos os profissionais neste processo, buscou-se, com base na reflesão sobre os vários momentos históricos de mudanças curriculares, analisar a inserção do enfermeiro na profissão. Os resultados obtidos evidenciaram a opinião vivenciada de que a prática profissional está desvinculada do processo formativo, não havendo, portanto, consonância entre o que é aprendido e o que é vivenciado. Conclui-se que, embora a enfermagem tenha buscado acompanhar a evolução científica e tecnológica, não atingiu o grau desejável de sua praxis, segundo opinião da população estudada.
\end{abstract}

\begin{abstract}
Concerned with the present situation of change in nursing practice and teaching in view of the various contributions proposed for graduate curricula in nursing and of the need for greater involvemente in this process on the part of all professionals, the authors investigated how the nurse fits in her profession on the basis of the various historical moments of curricular changes. It is concluded that, even though nursing has triep to keep up with the scientific and technological evolution, in the opinion of the population studied it has not reached the desired level of performance.

The results showed the opinion based on experience that professional practicer is not related to the training process, with no agreement between what is learned and what is actually experience. The professional nurse feels the need for a preparation more related to concrete reality and a greater connection between Theory and Practice.
\end{abstract}

\section{INTRODUC̣ÃO}

"A educação era (até agora) tarefa relativamente simples: bastava descobrir as necessidades da máquina social e depois recrutar e formar pessoal que a elas correspondesse..." (OLIVEIRA - LIMA).

A Enfermagem, no Brasil, encontrou seu berço na área de Saúde Pública, ao iniciar seus primeiros passos no Rio de Janeiro, na década de 20, colaborando para a eliminação da febre amarela. Nesta época, o país não tinha noções definidas sobre 0 significado e nem sobre a utilidade de uma escola de enfermagem, pois os poucos hospitais existentes estavam nas mãos de leigos ou religiosos (ALCÂNTARA, 1966).

Com a ocorrência da industrialização no país, a assistência curativa passou a predominar, por sua vez, provocando mudanças no sistema educacional e no setor de serviços de Saúde, passando os hopitais a absorverem maior número de enfermeiros do que os serviços de saúde pública.

\footnotetext{
* Professora Assistente do Departamento de Enfermagem, Psiquiatria e Ciências Humanas da EERP(USP)

* * Professora Assistente do Departamento de Enfermagem Materno Infantil da EERP (USP)
} 
As Escolas de Enfermagem também foram adaptandoos seus currículos, para responderem, a essa tendência e a necessidade de preparar profissionais para prestação de assistência de enfermagem em instituições hospitalares.

No fim da década de 70, houve um clamor dirigido a todos os profissionais de saúde, com a meta "Saúde para todos no ano 2.000", o que implicou em mudança radical do Sistema de Saúde vigente.

Neste contexto, OGUISSO (1982, p. 29-32) refere que o perfil do enfermeiro é definido como profissional generalista a nível de graduação, preparando para atuar nos programas de saúde a níveis de $1^{\circ}, 2^{\circ}$. e 3 . graus, com ênfase nas áreas materno-infantil e médicocirúrgica, com extensão à comunidade.

RHODUS (1979, p. 93) afirma que o ensino de Enfermagem, desde seu nascedouro, esteve sempre marcado pela profissionalização, pelo estágio prático e pelo ensino de campo, sendo boa parte da carga horária, ocupada pelo estágio em instituições de saúde.

De acordo com estes fatos, para entender o marco conceitual e estrutural dos currículos de enfermagem a nível de graduação, necessário se faz a análise preliminar dos condicionamentos históricos que demarcaram este marco, quer eles estejam implícitos ou explicitamente presentes.

Desta forma, pode-se dizer que existem, no momento, quatro tendências fundamentais que influenciaram os marcos conceituais e estruturais do ensino de enfermagem: 1) Ideologia Profissional - que caracteriza-se através do movimento tradicionalista, voltado para uma possível enfermagem liberal, refletindo um compromisso mais individual. 2) Mercado de Trabalho - voltado para atender ao mercado de trabalho, ligado à instituições públicas e privadas, com exigência a formação de especialistas capazes de atender toda sofisticação da assistência, quase que hospitalar. 3) Planos Oficiais de Saúde - que manifestam-se a partir da década de 70, com os programas de extensão e cobertura imprimidos nos programas oficiais, que através de várias estratégias, tem tentado influenciar o quadro de formação de pessoal de enfermagem. Esta tendência está ligada, no momento, ao movimento preventivista e à integração docente-assistencial, já em integração nas escolas, levando a um compromisso de reforma. Isto não tem modificado, de fato, a estrutura de prestação de serviços. 4) Compromisso Social - se inicia quando as escolas começam a perceber os conflitos entre as três tendências e partem para uma tomada de posição, ou seja, relfetir sobre a prática profissional, tendo em vista as reais necessidades da população, incorporando assim, o compromisso social dos profissionais, na tentativa de refletir e desenvolver um exercício crítico mais consciente, tal como afirmam PAIM et alii (1978, p. 111-15) e SILVA et alii (1979, p. 107-14).

Então, há necessidade de uma preocupação maior à determinação explícita de marcos conceituais pois, deve se buscar dinamicamente, à medida que o corpo docente e discente sintam-se responsáveis pelo estabelecimento dos mesmos. Se isto não ocorre, persistirá sempre o risco de se estabelecer marcos conceituais impossíveis de serem trabalhados dentro das escolas. Isto devido ao conhecimento do mesmo, por um dos elementos participantes que é o aluno e pelo possível desenvolvimento de uma interação divergente professor-aluno.

Portanto, faz-se evidente a importãncia de determinação de linhas de pesquisa nas diversas escolas. Segundo SILVA et alii (1979, p. 107-14) seria a única forma de se criar, através do exercício crítico entre professor-aluno, a oportunidade de se refletir, analisar e exercitar a crítica sobre a prática profissional.

MACEDO (1977, p.13-28) afirma que a formação superior deve superar a simples capacitação técnica, sem descuidá-la. Entretanto, deve-se educar para o compromisso social e para a mudança social. E, mais do que isto, a Enfermagem deve estar inserida neste processo.

\section{Revisão Bibliográfica}

Historicamente, sabe-se que a $1{ }^{a}$ reformulação da enf ermagem (Decreto $n$ ? 27 426, 14/11/49) não evidenciou concretas alterações continuando sem atender as necessidades educacionais de enfermagem no Brasil. BARROS (1985) enfoca que o mercado de trabalho requeria enfermeiros na área de Administração, Supervisão e Treinamento, enquanto o preparo estava centrado na formação de "enfermeiros de cabeceira".

Em 1950, surgem movimentos tas escolas, na associação de classe, com intuito de promover mudanças curriculares, de definir o código de ética, da necessidade de reconhecer sua realidade e principalmente da regulamentação do exercício profissional.

Surge o $2^{\circ}$ momento de mudança no ensino de enfermagem (Precer 271/62 - Conselho Federal de Educação), reflexo da lei de Diretrizes e Bases que define o Currículo Mínimo em 3 anos, incluindo Administração e excluindo Ciências Sociais e coloca Saúde Pública com 1 ano de especialização. BARROS (1985, p. 13-33) relata que nesta época, fomenta-se a especialização com base no processo de renda, com estímulo a privatização da assistência médica, no cuidado individual e curativo. Isto reflete no currículo de enfermagem, isolando a questão da Saúde Pública.

GERMANO (1983) cita que, na década de 70, docentes da escola de enfermagem da Universidade de São Paulo prepararam e encaminharam o anteprojeto do Currículo Mínimo que, com modificações, transformou-se no Parecer 163/72, com vigência ate hoje.

Engajado no processo, a ABEn passa a recomendar que o currículo de graduação em Enfermagem deva ser planejado, levando em conta as necessidades globais de saúde da população e a sua bagagem sócio- 
cultural, acompanhando o progresso das ciências educacionais, sociais, médicas e principalmente, apresentando certa flexibilidade, a fim de corresponder às necessidades regionais da saúde.

Em consonãncia com tais fatos, OGUISSO (1982, p. 21) afirma ainda que, "ora o ensino de enfermagem, seja para o nível de auxiliar, seja para o técnico, não poderá ser considerado como sondagens de aptidões e nem iniciação para o trabalho. Só pode ser uma forma de habilitação profissional. Para que essa habilitação profissional seja uma capacitação real e efetiva para o trabalho, o ensino não pode se restringir a uma sala de aula. Há que se ir para o laboratório, que no caso da enfermagem, como quase todas as ocupações da saúde, deve ser a instituição de saúde, isto é, os hospitais e os serviços de saúde pública".

Finalmente, tendo-se em vista às tendências para a década de 80, o currículo de enfermagem deve estar voltado ao movimento preventista (processo SaúdeDoença/níveis de prevenção); Integração Docente Assistencial (FERNANDES et alii, 1981, p. 164-74) e Extensão de Cobertura de Serviços - regionalização de ações, participação comunitária, como compromisso de reforma. Deve-se também fomentar, segundo SILVA et alii (1979), a reflexão crítica sobre a prática de enfermagem, prestação de serviços e necessidade da população (compromisso social), ideologia voltada para a afirmação do Status profissional - definição de papéis e busca de autonomia (compromisso individual), assim como a determinação do mercado de trabalho pelo Ministério de Previdência Social (compromisso com o Statu Quo).

Para ef etivação de tais propósitos, há necessidade de busca de novos conhecimentos científicos e culturais e trocas de experiências que são fundamentais para o profissional.

Para que se processem tais mudanças, necessário se faz, o preparo do corpo docente, o que também é uma tarefa árdua. Não será apenas por força de lei que se mudam mentalidades e hábitos arraigados. É preciso esforço gradual e consciente, vontade sincera para concretizar as mudanças a partir do sistema formador, sem descuidar do sistema utilizador. Para isto, OGUISSO \& CHAVES (1982) sugerem duas alternativas: a modernização do processo educacional e a integração docente assistencial, modernização esta, não só em termos de laboratórios ou corpo docente, mas também de métodos pedagógicos e de tecnologia educacional, para aumentar o processo educacional, para aumentar o processo educativo.

Preocupados com o momento atual de mudanças na prática e no ensino de enfermagem, tendo em vista as várias contribuições propostas para os currículos de graduação de enfermagem e a necessidade de uma maior participação de todos os profissionais que se engajam neste processo, buscou-se, com base na reflexão sobre os vários momentos históricos de mudanças curriculares, analisar a inserção do enfermeiro na profis- são. Isto implicou emlevantar alguns objetivos, a considerar.

\section{Objetivos}

Portanto, os objetivos do presente trabalho foram assim definidos:

1) Verificar a inserção do enfermeiro no trabalho em função de sua formação profissional;

2) A visão do enfermeiro frente a enfermagem tradicional e contemporânea, bem como sua visão atual de saúde.

\section{METODOLOGIA}

\section{Campo}

Participaram da pesquisa, enfermeiros de várias instituições (creches, centros de saúde, hospitais e escolas de enfermagem) de uma cidade do interior de São Paulo.

\section{População}

Trabalhou-se com uma amostra de 20 enfermeiros, de ambos os sexos, numa faixa etária de 23 a 35 anos de idade.

\section{Técnica}

Utilizou-se a entrevista oral, coletiva, tendo como instrumento, um questionário, constando de 2 partes:

IDENTIFICAÇÃO PESSOAL (sexo; idade; estado civil; renda mensal; nome da escola de sua formação; anos que conclui o seu curso; local de trabalho e cargo que ocupa).

QUESTÕES PROPRIAMENTE DITAS SOBRE O TEMA PROPOSTO (na sua opinião).

- Como você vê a Enfermagem Tradicional?

- Como você vê a Enfermagem Contemporãnea?

- 0 curso de enfermagem que você fêz o preparou para o seu desempenho profissional?

- Quais as maiores dificuldades encontrada no seu trabalho?

- De quando você se formou, o que mudou na Enfermagem e em você?

- Como hoje você define Saúde?

\section{Procedimentos}

Este questionário foi aplicado no início de um curso de didática, of erecido para enfermeiros da comunidade, com a finalidade de se detectar o perfil da classe e ter subsídios para trabalhar melhor com a população alvo, bem como ampliar ou restringir o conteúde programático do curso.

Antes da aplicação do instrumento, entregou-se folhas em branco para os entrevistados numa sala de au- 
la, com as questões previamente expostas na lousa. Em seguida, instruiu-se que todos lessem as questões no quadro negro e já respondessem direto na folha, sem copiá-las, apenas enumerando as questões, para economia de tempo. As mesmas deveriam ser respondidas de livre e espontãnea vontade, de forma simples, porém, honestas. 0 questionário foi respondido num período de 2 horas, e os respondentes, à medida que terminavam, se retiravam da sala.

Finalmente, tabulados os dados, criou-se espaço para um estudo mais ef etivo à luz de análise e reflexão dos temas prioritários propostos.

\section{RESULTADOS E DISCUSSÃO}

Apresentar-se-á os resultados seguidos de discussão, obedecendo a ordem do instrumento da pesquisa (Identificação pessoal e Questões propriamente ditas sobre o tema proposto).
Características da população: trabalhou-se com 28 enfermeiros, de ambos os sexos, predominando o feminino (96\%), maioria entre 26 e 35 anos (67\%), sendo $54 \%$ de solteiros, cujas formações acadêmicas se deram nas seguintes escolas de enfermagem dos estados: SÃO PAULO: EERP-USP (67\%) e FCSBM-SP (25\%); GOIÁS: UCG (4\%) e MINAS GERAIS: UFMG (4\%). Portanto podese verificar que os enfermeiros pesquisados se encontram em idade adulta jovem, de produção profissional na média, com 10 anos de formados, estando $61 \%$ atuando no ensino; $28 \%$ na assistência; $4 \%$ em creche e $7 \%$ desempregados.

Questões sobre o tema proposto: as questões elaboradas permitiram a emissão de vaŕias respostas que através da análise destes dados, estão englobadas em categorias e enunciados, correspondentes a cada questão, sendo que uma delas permitiu classificação numérica.

\section{QUESTÃO 1: COMO VOCÊ VÊ A ENFERMAGEM TRADICIONAL?}

QUADRO 1: Uma visão do enfermeiro, caracterizando a enfermagem antiga.

\section{ENFERMAGEM ANTIGA}

$\%$

- ' Fundamentalmente curativa' .

-“ Caritativa, submissa, generosa, servil”.

- " Sem espaço, fechada".

-“ Acrítica, alienada, sem bases científicas, desvalorizada".

-“Mais ligada aos aspectos assistenciais (técnicas e realização de tarefas)".

- “ Preparava melhor o profissional pelo pequeno número de alunos".

_." Considerada de péssimo conceito e qualidade".

- "Sem conhecimento teórico por falta de pesquisa".

- "Embora empírica, era mais humanizada".

-“"Lutando pelo espaço".

- "Formação rígida, mas deixando fortes raízes".

- "Primitiva/praticada por leigos e voluntários".

- “Tentando acompanhar a situação econômica e política”.

$\begin{array}{rr}\text { n } & \% \\ 28 & 100 \\ 28 & 100 \\ 26 & 93 \\ 24 & 86 \\ 22 & 78 \\ 18 & 64 \\ 11 & 39 \\ 8 & 28 \\ 7 & 25 \\ 6 & 21 \\ 5 & 18 \\ 5 & 18 \\ 5 & 18\end{array}$

A população evidenciou a enfermagem tradicional fundamentalmente como curativa, caritativa, acrítica, alienada, desvalorizada, etc. Embora tendo sido primordialmente apresentado sob este prisma, há de se considerar, contudo, o enfoque apresentado pelos en- fermeiros estudados sobre a preparação do profissional quando referiram sobre o pequeno número de alunos nas escolas de enfermagem (64\%), o que denota uma característica de formação mais individualizada e uma prática mais humanística.

\section{QUESTÃO 2: COMO VOCÊ VÊ A ENFERMAGEM CONTEMPORÂNEA?}

QUADRO 2: Uma visão do enfermeiro caracterizando a enfermagem moderna.

QUADRO $2_{\text {a }}$ - A enfermagem moderna buscando identidade própria e participando da política de saúde.

- "Mais aberta e flexível, com tentativa de organização de categorias, talvez pela consciência crítica de seus profissionais ou pela sua formação".

- "Mais consciente, independente, autônoma, liberal".

- "Mais valorizada e reconhecida pelos próprios profissionais da saúde e pela comunidade".

- "Ampliando seu espaço e campo de atuação".

- "Assumindo seus papéis, se envolvendo cada vez mais e comprometendo-se com a profissão". 
- "Aspecto profissional sobrepondo-se ao assitencial".

- "Começando a se envolver com a política de saúde, porém com pouca influência neste setor”.

- "Começando a questionar seu papel".

- "Com perspectiva de melhoria na qualidade de serviço prestado, com relação ao paciente e gratificação profissional”.

- "Com necessidade de reavaliação dos currículos, em função do profissional a ser formado".

- "Com necessidade de reflexão sobre a formação do profissional de $3^{\circ}$ grau e reestruturação da formação do profissional em benefício de sua qualificação".

- "Frente à legitimidade do exercício profissional e estudando a evolução do enfermeiro, percebe-se que esta, como as outras profissões de saúde, acompanha as mudanças sócio-econõmicas, atuando nas necessidades do sistema político-social vigente".

- "Tentando seguir as diretrizes da política nacional".

- "Com a mudança no setor e a necessidade de se refletir sobre a saúde como um processo, começam a reforçar mudanças nos padrões da enfermagem como um todo".

QUADRO $2_{\mathrm{b}}$ : A enfermagem moderna na busca de maior desenvolvimento técnico e científico.

- "Desenvolvendo pesquisa científica".

- "Desenvolvendo espírito crítico, tendendo a uma auto-exigência, a praticar a reflexão e desenvolver um conhecimento científico próprio".

- "Fomentando debates e discussões".

- "Fugindo do tecnicismo e buscando um corpo de conhecimento próprio".

- "Procurando fundamentação teórica, com marcos filosóficos e questionando sua prática".

- "Ampliando seu conhecimento, cada vez mais".

- "Preocupando-se com os aspectos científicos da profissão".

- "Abrindo e/ou ampliando cursos de pós-graduação, desenvolvendo uma consciência crítica”.

- "Melhorando e divulgando conhecimentos, evidenciando necessidade de pesquisa e de avanço tecnológico".

- “O enfermeiro atual desenvolvendo uma ação mais complexa: coordena e orienta o desenvolvimento da prática do enfermeiro; planeja a assistência, executa o cuidado, orienta o paciente, bem como desenvolve pesquisa na área".

- "As funções do enfermeiro são 5: assistencial, administrativa, integrativa, educativa e de pesquisa".

QUADRO $2_{c}-$ A enfermagem moderna em crise.

- "Desestimulada, submissa, servil, alienada, acomodada, pouco participante".

- "Tecnicamente bem, mas o paciente está cada vez mais despersonalizado".

- "Em crise, necessitando de maior reflexão".

- "Desenvolvendo função puramente burocrática".

- "Total desinteresse do aparelho formador (com relação professor, aluno, paciente)".

- "O atendente assumindo e cumprindo as funções do enfermeiro".

- "O enfermeiro com pouco conhecimento científico".

- “As escolas cumprindo o conteúdo teórico do programa mas diminuindo as atividades em estágios".

- "Espaço do enfermeiro ameaçado".

Conforme os enunciados apresentados, verifica-se que há um enfoque maior nas categorias $2_{\mathrm{a}} \mathrm{e} 2{ }_{\mathrm{b}}$, evidenciando a enfermagem enquanto participante da política de saúde, buscando identidade própria, desenvolvendo seu corpo de conhecimento, bem como, ampliando o aspecto técnico e científico da profissão. Por outro lado, o quadro 2 c evidencia uma contra-posição destes enunciados, caracterizando a enfermagem como estando em crise. Diante de tais enunciados, fica um questionamento a se efetivar. Qual o real posicio- namento da enfermagem atual? Porque os enfermeiros evidenciam a profissão com excesso ou falta de idealização? Será, provavelmente, na tentativa de defender uma desesperança ou uma realidade um tanto obscura a qual se tem dificuldade de trabalhar?

Não resta dúvida que a enfermagem cresceu - evoluiu, e muito. 0 que se há de refletir é que, com toda essa evolução, o que está sendo deixado para trás? Neste processo, não se pode esquecer da união de classe... redefinição de papéis... a prática social... as ideologias... 
o mercado de trabalho... o currículo... ausência de pesquisas operacionais e integração docente-assistencial... e muitos outros aspectos que podem estar desvinculados da profissão.

\section{QUESTÃO 3 - O CURSO DE ENFERMAGEM QUE VOCÊ FEZ, O PREPAROU PARA O DESEMPENHO PROFISSIONAL?}

QUADRO 3 - De certa forma o curso de graduação de enfermagem preparou o enfermeiro para o desempenho profissional.

QUADRO $3_{\mathrm{a}}$ - 0 curso de enfermagem preparando para o desempenho da profissão, mas, às vezes, preparando de forma irreal para as funções exigidas na prática.

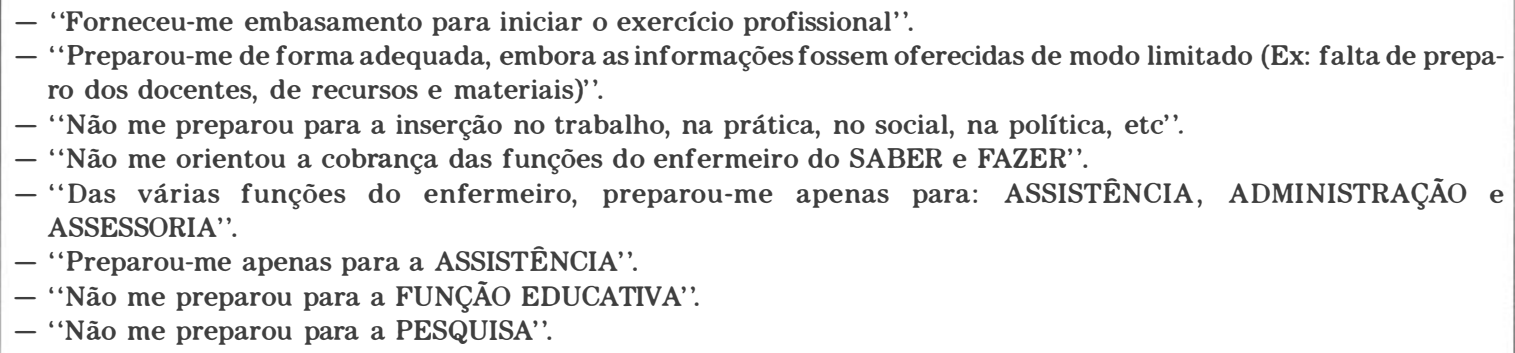

QUADRO $3_{b}-0$ curso de enfermagem preparando para o exercício da profissão, mas há necessidade de ampliar a educação continuada na área.

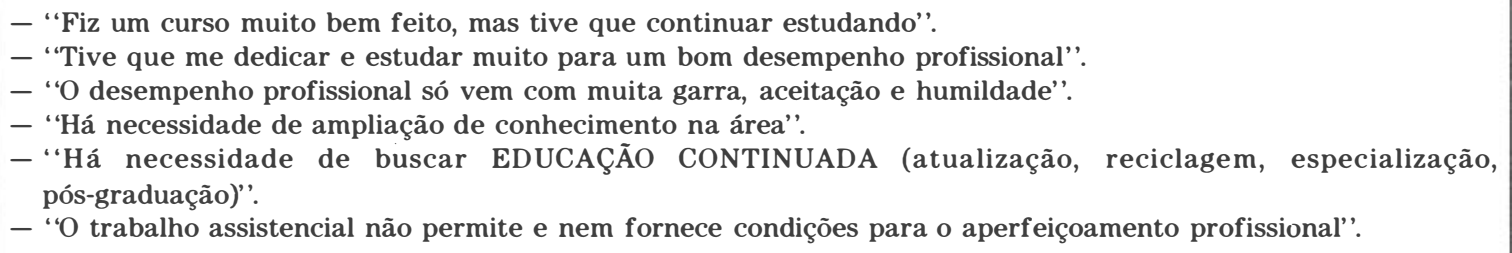

QUADRO $3_{\mathrm{c}}-0$ curso de enfermagem preparando de forma irreal para o desempenho do profissional.

\footnotetext{
- "Não considerou a política de saúde, o aparelho formador de mão de obra em enfermagem, não apresentando a situação real da necessidade do enfermeiro na sociedade brasileira".

- "Não evidenciou as dificuldades da atuação na prática, apresentando o profissional um comportamento dualista frente ao que se aprende ao que se faz".

- 'Não enfocou o relacionamento profissional com a equipe de enfermagem bem como o papel do enfermeiro na equipe multiprofissional".

- "Apresentou a teoria desvinculada da prática".

- "Não ofereceu a visão do mercado de trabalho".
}

De acordo com as respostas emitidas na questão 3 , conforme os quadros de 3 a 3 , $50 \%$ dos enfermeiros pesquisados, responderam que o curso de graduação de enfermagem que fizeram, os prepararam relativamente bem, embora não os tivessem preparado para algumas funções que o enfermeiro exerce na prática (quadro 3 a).

0 quadro $3{ }_{b}$ evidencia a necessidade da educação continuada em enfermagem representando opinião de
$18 \%$ da amostra. Há de se considerar, neste aspecto, 4 itens fundamentais: o papel da universidade na formação dos profissionais; a função da própria escola; o próprio profissional e peculiaridades da profissão. $\mathrm{Da}$ universidade e da própria escola: entende-se que as mesmas não podem of erecer à sociedade um profissional acabado; do profissional: este deve estar consciente da necessidade de se reciclar e se aperfeiçoar; da profissão: pela caracterização das grandes transformações 
ocorridas na prática profissional. Portanto, acreditase que, a ef etivação deste processo, possa ser caracterizada com as estratégias da Integração-DocenteAssistencial e o desenvolvimento da Pesquisa Operacional. No quadro 3 , $32 \%$ dos enfermeiros referiram ter uma formação irreal para o desempenho profissional. Portanto, constatou-se que a maioria dos enfer- meiros (68\%) referiu ter tido um curso que os preparasse para o desempenho profissional, embora com algumas deficiências na formação e, os demais (32\%) com formação irreal. Há de se lembrar que a amostra estudada, abrangeu enfermeiros formados em diferentes escolas e com atuação em diversas áreas profissionais.

\section{QUESTÃO 4 - QUAIS AS MAIORES DIFICULDADES ENCONTRADAS NO SEU TRABALHO?}

QUADRO 4 - Dificuldades do enfermeiro no trabalho.

QUADRO $4_{\mathrm{a}}$ - Dificuldades do enfermeiro relacionadas à falta do preparo para as atividades didáticas e educativas.

\footnotetext{
— "Falta de conhecimentos básicos de didática para o desempenho da docência (ministrar aulas e transmitir conhecimentos)".

- "Dificuldades na elaboração de PLANEJAMENTO DIDÁTICO: planejamento de ensino, de curso, de unidade, de aula; formulação de programas; construção de objetivos; motivação e avaliação da aprendizagem de alunos, pacientes e funcionários".

- "Dificuldades no planejamento diário (plano de ação)".
}

QUADRO $4_{\mathrm{b}}$ - Dificuldades do enfermeiro relacionadas à inserção da profissão no setor saúde e no contexto social.

- "Desvalorização da profissão".

- "Falta de reconhecimento do papel do próprio enfermeiro".

- "Baixa remuneração salarial".

- "Dificuldades ligadas às injustiças sociais e problemas políticos".

- "Integração do corpo de conhecimento técnico-científico, com questões mais gerais que condicionam o trabalho em saúde’'.

- "Dificuldades para o profissional contribuir para as verdadeiras necessidades da população brasileira frente à saúde’”.

QUADRO $4_{c}$ - Dificuldades do enfermeiro relacionadas aos problemas de ordem profissional e institucional.

- "Não liberação da instituição para participação de cursos, congressos e "conclaves similares".

- "Falta de oportunidade para treinamento e reciclagem".

- "Sobreposição de tarefas, além de designadas pela prática profissional".

- "Sobrecarga de atividades e excesso de trabalho".

- "Exigência e cobrança excessivas no trabalho".

- "Limitações do profissional e mercado de trabalho".

QUADRO $4_{\mathrm{d}}$ - Dificuldades do enfermeiro encontradas no trabalho devido ao preparo profissional obtido através da escola.

- "Falta de experiência prática (insegurança profissional)".

- "Dificuldades em aplicar os conhecimentos adquiridos na escola, corretamente .

- "Existência de um comportamento dualista entre o que aprendeu e o que executa".

_ "Dificuldade no relacionamento com as equipes de saúde e a multiprofissional". 
Tendo-se em vista que $61 \%$ dos enfermeiros, estão ligados à docência e sendo o instrumento aplicado previamente à um curso de Atualidade em DIDÁTICA E CURRÍCULO, sobrepuzeram-se a categoria e enunciados ligados à problemas didáticos e educativos (53\%) sobre os demais quadros. Em função de tais dificuldades, procurou-se, dentro do curso proposto, of erecer tais temas, seguidos de discussões e debates.

Constatou-se ainda que, além destas dificuldades, os enfermeiros referiram outras como ligadas à inserção da própria profissão no setor saúde e no contexto social; à problemas de ordem profissional e institucional e da sua própria formação. (quadros $4_{\mathrm{a}}$ a $4_{\mathrm{d}}$.

Entende-se, no entanto, que os enunciados no quadro 4 , não são restritos apenas à formação do enfermeiro, sendo características peculiar de qualquer área de formação profissional.

\section{QUESTÃO 5 - DE QUANDO SE FORMOU, O QUE MUDOU EM VOCÊ E NA ENFERMAGEM?}

QUADRO 5 - Aspectos positivos e negativos evidenciados pelos enfermeiros depois da formação acadêmica.

QUADRO $5_{\mathrm{a}}$ - Aspectos positivos apresentados pelos enfermeiros em termos pessoais e da enfermagem, depois do término da graduação.

Pessoalmente:

- "Hoje, depois de muito trabalho, adquiri amadurecimento".

- "Hoje tenho uma visão mais crítica sobre a profissão".

- "Adquiri mais confiança, enquanto pessoa e profissional".

- "Ampliando meus conhecimentos, aprimorando aspecto profissional".

- "Hoje já lidero o trabalho e tenho bastante segurança no que faço".

- "Ainda me sinto insegura (formei-me recentemente)".

Enfermagem:

- "Evolução dos cursos de pós-graduação, atualização, etc. em enfermagem”.

- "O aluno é mais participante".

- “Ampliação do campo de estágio".

- "Os programas são mais abrangentes, permitindo maior oportunidade na teoria e na prática da Enfermagem (Saúde Pública)".

- "Implantação dos AIS, onde se sente que a enfermagem conquista amplo espaço".

- "Renoção dos currículos".

- "Ampliação do campo de atuação".

- "Fomento de questionamento, novas idéias e preocupação com a formação do profissional".

- "Classe mais unida, fazendo-se presente em todos movimentos importantes".

- "Aprimoramento no conhecimento, nas técnicas e no relacionamento".

- "Alguns núcleos de mudança na Política Nacional de Saúde e reflexo da necessidade de se ver saúde como processo, começam a reforçar a mudança nos moldes da enfermagem como um todo".

- "A abrangência da enfermagem - em termos de atuação; o desenvolvimento técnico-científico da área, possibilitando um maior desenvolvimento da enfermagem enquanto busca uma ciênca própria”.

QUADRO $5_{b}$ - Aspectos negativos apresentados pelos enfermeiros em termos pessoais e da enfermagem, depois que terminaram a graduação.

Pessoalmente:

_ "Diminuindo o estímulo e o entusiasmo pela profissão (antes + idealista)".

- "Com maiores dificuldades de trabalhar com a equipe".

- "Continuo insegura no trabalho".

- "Até hoje continuo como auxiliar de enfermagem para sobreviver e por falta de mercado de trabalho".

- "Carência cada vez maior de tempo e oportunidade para eu fazer cursos".

- "Diminuição de chances em divulgar meus trabalhos científicos".

- "Redução de espaço para discutirmos problemas de serviço". 
Na Enfermagem:

- "Profissionais adaptando-se a ordens e obedecendo-as".

- "Escassez do mercado de trabalho".

- "Descrédito do profissional pelos próprios profissionais".

- "Desinteresse do profissional em aprender, crescer, trabalhar e lutar",

- "Dificuldade do profissional integrar docência, pesquisa e assistência".

- "Má formação do profissional que vem vindo (queda do ensino; desestimulação e desinteresse do aluno; número elevado de alunos; baixo nível de conhecimento dos alunos que vem para a universidade; falta de conhecimento didático do docente; perda do sentido ético da profissão no ensino, etc)".

- "A descoberta de que o enfermeiro por si só não modifica os aspectos negativos da instituição em que atua".

- "Passividade total da classe".

Constata-se no quadro 5 a que, apesar das dificuldades e problemas enfrentados pela amostra estudada, os enfermeiros admitem as transformações ocorridas na enfermagem e no profissional, que ao nosso ver refletem características da situação de crise no setor social e da saúde e conseqüente período de transição da profissão. Quanto aos aspectos negativos no quadro $5_{\mathrm{a}}$, representa uma avaliação crítica da situação real da enfermagem que deve ser direcionada para uma análise reflexiva mais intensa.

\section{QUESTÃO 6 - HOJE, COMO VOCÊ DEFINE SAÚDE?}

QUADRO 6 - Visão atual do conceito de saúde emitido pelos enfermeiros da amostra.

- "Completo bem estar bio-psico-social (espiritual) e não apenas ausência de doença".

- "É o conjunto bio-psico-social em constante adaptação junto ao meio ambiente, sem intercorrências que o impeçam a tal, sejam as mesmas de 1 ou dos 3 sistemas complexos citados".

- "São os aspectos bio-psico-social se fundindo, com o perfeito equilíbrio e liberdade de ação".

- "É o bem estar global: no aspecto biológico (o perfeito equilíbrio das funções orgânicas), nos aspectos psico, social e espiritual, o indivíduo ajustado e participativo em suas realizações, num ambiente".

- "É o equilíbrio de tudo que rege o nosso organismo".

- "É a satisfação das necessidades básicas".

- "É o indivíduo se sentir feliz".

- "É estar bem relacionado com o meio ambiente".

- "É integração do meio interno com o meio externo".

- "É estar bem na sociedade, engajando trabalho, lazer, relacionamento, etc".

- "É desenvolver aspectos saudáveis".

- "É interceptar os fatores que interfiram na saúde: social-econômico-político".

- "É o cumprimento dos deveres humanos e não só ausência de saúde".

- "É o processo do perf eito equilíbrio entre as funções fisiológicas, internas do indivíduo, atendimento das necessidades básicas, equilíbrio nas relações deste consigo mesmo e com o meio ambiente'.

- "É uma condição para poucos dada as injustiças sociais (pobreza e miséria que rodeia a humanidade)".

A questão acima referida teve como objetivo caracterizar a visão atual do enfermeiro referente ao conceito de saúde constatando que permaneceu o conceito adquirido na sua formação acadêmica, ou seja, os conceitos teóricos expressivos pela OMS (64\%).

\section{CONCLUSÃO}

Conclui-se no presente trabalho que a visão tradicional e contemporânea da enfermagem e a inserção do profissional no trabalho se dá com base nas seguintes proposições:

a) a enfermagem tradicional é fundamentalmente curativa, caritativa, submissa, acrítica, alienada, des- valorizada, embora mantendo uma formação mais individual e uma prática mais humanitária;

b) a enfermagem contemporânea é mais participante na política de saúde, autônoma, buscando sua identidade própria, empenhada no desenvolvimento de seu corpo de conhecimento, ampliando o aspecto técnico-científico da profissão.

c) em contraposição ao enunciado acima o enfermeiro questiona sobre a profissão evidenciando um momento de crise na enfermagem ligado a problemas de ordem individual, profissional, institucional e social.

d) o enfermeiro se posicionou em relação aos questionamentos de sua profissão de suas formas extremas, ora de forma idealista e portanto com predominância de posicionamento conservador, ora crítica, pre- 
dominando uma postura de reflexão e questionamento sobre a profissão e sua inserção na prática profissional.

\section{REFERÊNCIAS BIBLIOGRÁFICAS}

1. ALCÂNTARA, G. A Enfermagem Moderna como Categoria Profissional: obstáculos à sua expansão na sociedade brasileira. São Paulo, Escola de Enfermagem da USP. 1963. Tese de Cátedra.

2. BARROS, S.M.P.F. de. política de Educação em Enfermagem. In: ANAIS DO SEMINÁRIO: A PRÁTICA DE ENFERMAGEM E O CURRÍCULO DE GRADUAČÃO, Rib. Preto, Escola de Enfermagem da USP; 1985, p. 13-33.

3. FERNANDES, L.L. et alii Integração do Ensino com a Assistência na Enfermagem: uma prioridade para o campo clínico. Revista Brasileira Enfermagem. Distrito Federal, 34-164-74, 1981.

4. GERMANO, R.M. Educação e Ideologia da Enfermagem no Brasil. São Paulo, Editora Cortez, 1983.
5. MACEDO, C.Q. de Recursos Humanos para a Saúde - Temas of iciais básicos. Congresso Brasileiro de Higiene, São Paulo, 19, 1977. p. 13-28.

6. OGUISSO, T. A Enfermagem e as Habilitações à nível de $2^{\circ}$. grau. In: ANAIS DO CONGRESSO BRASILEIRO DE ENFERMAGEM, 34. Porto Alegre, 1982. p. 21.

7. OGUISSO, T. Saúde e Educação: estratégia de mudança. In: ANAIS DO CONGRESSO BRASILEIRO DE ENFERMAGEM, 34, Porto Alegre, 1982. P. 29-32.

8. OGUISSO, T. \& CHAVES, M.M. Saúde, uma Estratégia de Mudança. Rio de Janeiro, Editora Guanabara Dois, 1982.

9. PAIM, L. et alii As Inovações no Ensino de Enfermagem Face a Assistência à Saúde da População: possibilidades e limitações. In: ANAIS DO CONGRESSO BRASILEIRO DE ENFERMAGEM, 30, Belém, 1978. p. 111-15.

10. RHODUS, C.C. Preparo e Aperfeiçoamento de Recursos Humanos para a Enf ermagem. In: ANAIS DO CONGRESSO BRASILEIRO DE ENFERMAGEM, 31, Fortaleza, 1979. p. 93.

11. SILVA, A.L.C. et alii Marco Conceitual e Estrutural dos Currículos dos Cursos de Graduação em Enfermagem. In: ANAIS DO CONGRESSO BRASILEIRO DE ENFERMAGEM, 31, Fortaleza, 1979, P. 107-14. 